\title{
Conservative management of gastric emphysema with hepatoportal venous gas
}

\section{Ceen-Ming Tang, ${ }^{1,2}$ Shadi S Yarandi, ${ }^{2}$ William Harlan Laxton, ${ }^{3}$ Mouen A Khashab ${ }^{2}$}

${ }^{1}$ University of Oxford, Oxford, UK

${ }^{2}$ Division of Gastroenterology and Hepatology, Johns Hopkins Hospital, Baltimore, Maryland, USA

${ }^{3}$ Department of Radiology, Johns Hopkins Hospital, Baltimore, Maryland, USA

\section{Correspondence to}

Ceen-Ming Tang, ceenmingtiffanytang@gmail.com

Accepted 8 July 2015

\section{DESCRIPTION}

A 43-year-old man with a history of viral hepatitis and active intravenous drug use presented with a 4-day history of severe nausea and coffee-ground emesis, followed by acute onset of colicky abdominal pain and non-bloody diarrhoea. On examination, he was tachycardic, but otherwise haemodynamically stable and afebrile. There was tenderness in the right upper quadrant, with no rebound or guarding and bowel sounds were normoactive. Initial laboratory investigations revealed raised urea of $24 \mathrm{mM} / \mathrm{L}$, normal lactate and no leucocytosis.

A CT of the abdomen and pelvis with contrast revealed gastric pneumatosis (figure 1) with hepatoportal venous gas (HPVG; figure 2) and signs of parenchymal infarction (figure 3). This prompted a surgical consult, which, on the basis of the patient's stable vitals, unlikelihood of ischaemia (figure 4) and lack of pneumoperitoneum, recommended conservative management with intravenous fluids, ondansetron, ranitidine and ertapenem. He improved rapidly, with an ultrasound $24 \mathrm{~h}$ post-presentation demonstrating complete resolution of HPVG. An oesophagogastroduodenoscopy $72 \mathrm{~h}$ post-admission showed gastritis (figure 5) and no ulcers or necrosis. He was discharged in stable condition.

Gastric pneumatosis may represent benign gastric emphysema (GE), which resolves spontaneously, or

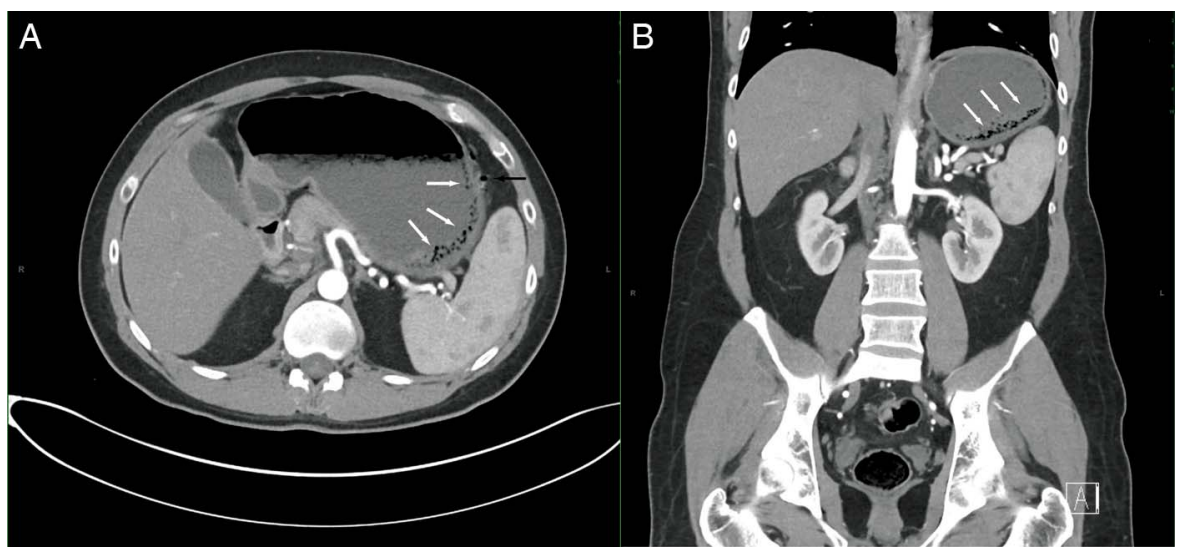

Figure 1 Marked pneumatosis extending from the fundus along the greater curvature of the stomach (white arrows) with gas in the left gastroepiploic veins (black arrow). (A) Transverse; (B) Coronal.

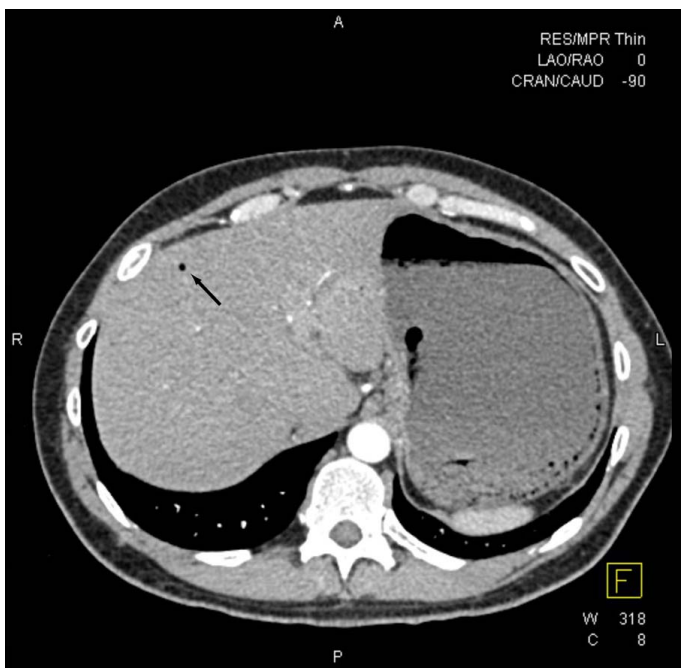

Figure 2 Portal venous gas (black arrow), with additional mesenteric venous gas, is most evident in the left gastric artery and gastroepiploic artery territories.

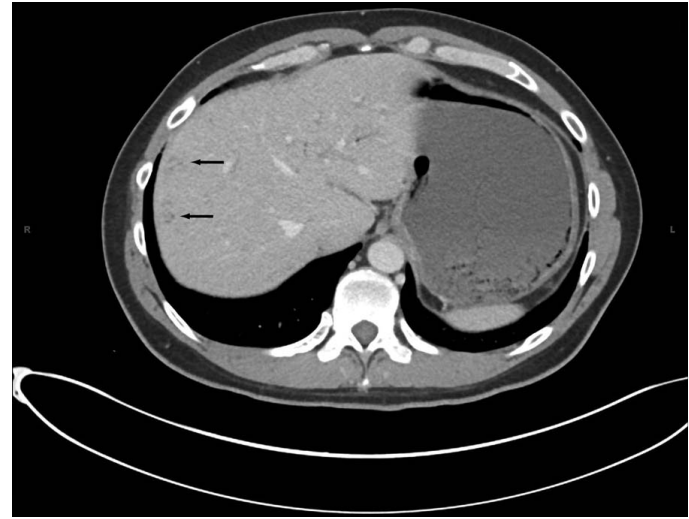

Figure 3 Small peripheral wedge-like opacities throughout the right hepatic lobe are suspicious for very early parenchymal infarcts. 


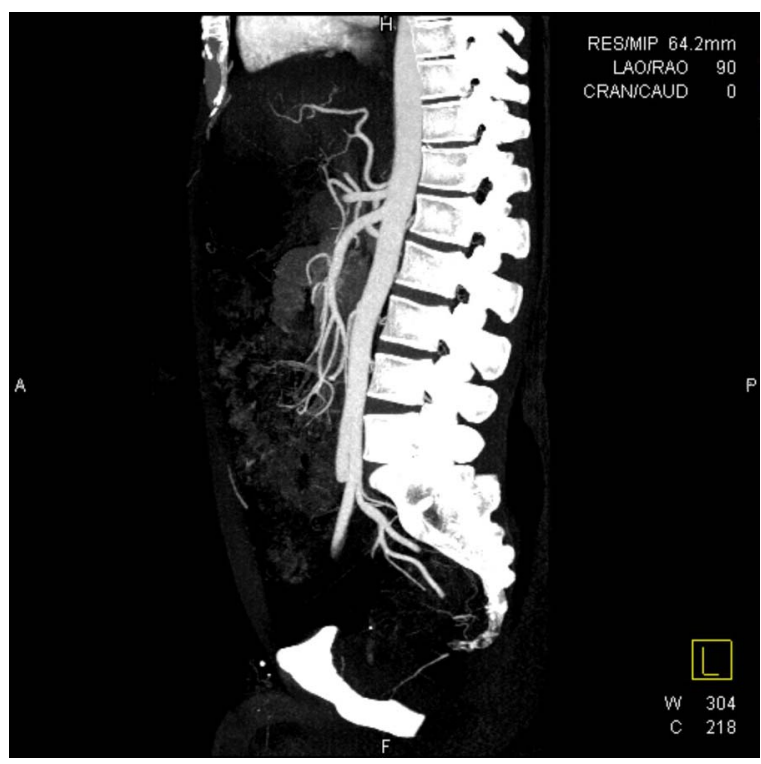

Figure 4 Central mesenteric arterial vasculature is patent, making ischaemia unlikely.

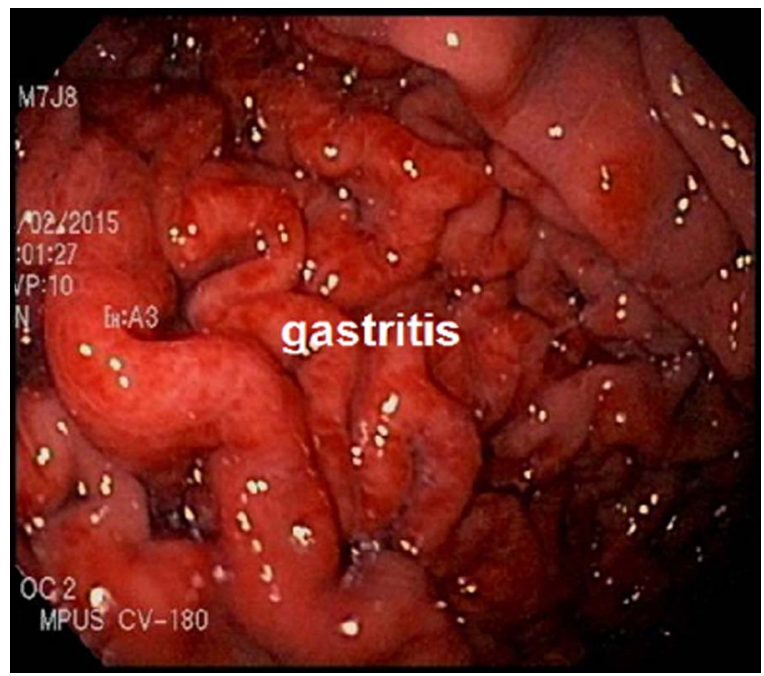

Figure 5 Oesophagogastroduodenoscopy (OGD) showed erythematous gastritis in the stomach, most pronounced in the fundus and proximal body extending to the antrum. Biopsy showed reactive epithelial changes. emphysematous gastritis, which has a high mortality. ${ }^{1}$ While this patient's history of active substance abuse and evidence of HPVG were concerning for emphysematous gastritis, his haemodynamic stability and rapid symptomatic resolution was more consistent with a viral gastroenteritis. ${ }^{2}$ Severe vomiting may cause a mucosal tear, leading to coffee-ground emesis. Subsequent transmural diffusion of air through the defect may result in GE and HPVG.

\section{Learning points}

- Gastric pneumatosis, which refers to the presence of gas within the wall of the stomach, is a rare finding. It represents a spectrum of conditions ranging from benign gastric emphysema, to life-threatening emphysematous gastritis.

- Hepatoportal venous gas may be seen in benign gastric emphysema and emphysematous gastritis because the left gastroepiploic veins are part of the portal venous system. It is not an indication for surgery on its own, and patients with stable vital signs can be managed conservatively.

- Benign gastric emphysema may be caused by severe vomiting, and resolves spontaneously with supportive treatment.

Twitter Follow Ceen-Ming Tang at @TangCeenMing

Acknowledgements The authors would like to acknowledge all other staff involved in the care of this patient.

Contributors C-MT collected data and wrote the case report. WHL assisted with the interpretation and selection of images, and offered additional comments from an imaging perspective. SSY and MAK revised the case report.

Competing interests None declared.

Patient consent Obtained.

Provenance and peer review Not commissioned; externally peer reviewed.

\section{REFERENCES}

1 López-Medina G, Castillo Díaz de León R, Heredia-Salazar AC, et al. Gastric emphysema a spectrum of pneumatosis intestinalis: a case report and literature review. Case Rep Gastrointest Med 2014;2014:891360.

2 Parikh MP, Sherid M, Ganipisetti V, et al. Vomiting-induced gastric emphysema and hepatoportal venous gas: a case report and review of the literature. Case Rep Med 2015;2015:413230.

Copyright 2015 BMJ Publishing Group. All rights reserved. For permission to reuse any of this content visit http://group.bmj.com/group/rights-licensing/permissions.

BMJ Case Report Fellows may re-use this article for personal use and teaching without any further permission.

Become a Fellow of BMJ Case Reports today and you can

- Submit as many cases as you like

- Enjoy fast sympathetic peer review and rapid publication of accepted articles

- Access all the published articles

- Re-use any of the published material for personal use and teaching without further permission

For information on Institutional Fellowships contact consortiasales@bmjgroup.com

Visit casereports.bmj.com for more articles like this and to become a Fellow 